Review Article

\title{
Issues and challenges of pediatric anesthesia in Bangladesh
}

\begin{abstract}
Geographically Bangladesh is located in an area where natural calamities like flood, cyclone, and drought are very common. The country is hugely populated $(1252 / \mathrm{Sq} \mathrm{km})$ due to its livable plain terrain with a good reserve of natural resources but as usual, we have a developing health management system. So, as a non-earning member of family women and children is the most vulnerable group of society. Children constitute more than one third (51.3million) of total population on the other hand woman constitute almost half (49.40\%) as well. Due to low Gross Domestic Product (GDP), allocation of budget in health $(0.92 \%$ of GDP) specifically for addressing children and maternal health is not sufficient. Despite the diversity in their geographical, linguistic, and political structures, Afghanistan, Bangladesh, Bhutan, India, the Maldives, Nepal, Pakistan, and Sri Lanka face common health challenges. Moreover socioeconomic status of these countries differs very little, even though Bangladesh had achieved United Nations Award for successful reduction of infant (28.2/1000) and maternal mortality rate $(170 / 1000)$ on Millennium Development Goals-4 during the $65^{\text {th }}$ United Nations General Assembly.

Combined Military Hospital, Dhaka is a 1500 beds tertiary care teaching hospital which has 30 beds pediatric surgery ward, 130 beds pediatric medical ward, 10 beds neonatal ICU, 10 beds pediatric ICU and 36 beds adult ICU as well. On an average 100 routine, pediatric surgery cases are being performed in this hospital in every month. Amongst those common surgical diseases are hernia, anorectal malformation (ARM), hirschsprung's disease, tongue tie, appendicitis, intussusceptions, rectal polyp, idiopathic hypertrophic pyloric stenosis (IHPS), hydrocephalus, hypospadias and less common surgical diseases are esophageal atresia with/without fistula, intestinal atresia, eventration of diaphragm, diaphragmatic hernia, mesenteric cyst, myelomeningocele, posterior urethral valve (PUV), undescended testes (UDT), gastroschisis, omphalocele etc.

The hospital is rich with allied health professionals in almost all discipline especially pediatric cardiology, pediatric cardiac surgery. Though this hospital has enough hospital beds and plenty of patients yet lack skill doctors \& paramedics. In terms of patients, this hospital is managing a maximum number of patients with minimum resources and staffs. Professional challenges are capacity building, poor socioeconomic and poor nutritional states, inadequate social awareness programs, delayed reporting sick to hospital \& delayed interventions, extreme resources constrains and to combat those challenges day to day improvisations are like improvised way of maintaining airway, improvisation of warming up patients, fluids, blood and clinical monitoring of patients instead of sophisticated electronic monitoring devices.
\end{abstract}

Keywords: combined military hospital, children, Bangladesh, maternal health
Volume 10 Issue $6-2018$

\begin{abstract}
Abul Kalam Azad,' Mohammad Safi Ullah²
'Associate Professor, Combined Military Hospital, Bangladesh

${ }^{2}$ Consultant Internist, King Salman Hospital, Riyadh, Saudi Arabia

Correspondence: Abul Kalam Azad,Associate Professor, Combined Military Hospital, Bangladesh, Tel 0088017I5010956, Email azadI00894@gmail.com
\end{abstract}

Received: August 03, 2018 | Published: November 13, 2018

\section{Background}

Geographically Bangladesh is located in an area where natural calamities like flood, cyclone, and drought are very common. The country is hugely populated $(1252 / \mathrm{Sq} \mathrm{km})$ due to its livable plain terrain with a good reserve of natural resources but as usual, we have developing health management system. So, as a non-earning member of family women and children is the most vulnerable group in society.

\section{Socioeconomic state $\&$ health state}

Children constitute more than one third (51.3million) of the total population on the other hand women constitute almost half (49.40\%) as well. Due to low GDP, allocation of budget in health $(0.92 \%$ of GDP) specifically for addressing children and maternal health is not sufficient. Despite the diversity in their geographical, linguistic, and political structures, Afghanistan, Bangladesh, Bhutan, India, the Maldives, Nepal, Pakistan, and Sri Lanka face common health challenges. Moreover socioeconomic status of these countries differs very little, even though Bangladesh has achieved United Nations Award for successful reduction of the infant (28.2/1000) and maternal (170/1000) mortality rate on MDG 4 during the $65^{\text {th }}$ UNGA.

\section{Combined military hospital, Dhaka}

Combined Military Hospital (CMH), Dhaka is a 1500 beds tertiary care teaching hospital which has 30 beds paediatric surgery ward, 130 beds paediatric medical ward, 10 beds neonatal ICU, 10 beds paediatric ICU and 12 beds adult ICU as well. On an average 100 routine, paediatric surgery cases are being performed in every month. The hospital is rich with allied health professionals in almost all discipline especially paediatric cardiology, paediatric cardiac surgery (Figure 1). ${ }^{1}$

'Logbook. Combined Military Hospital, Dhaka; 2012-2016. 


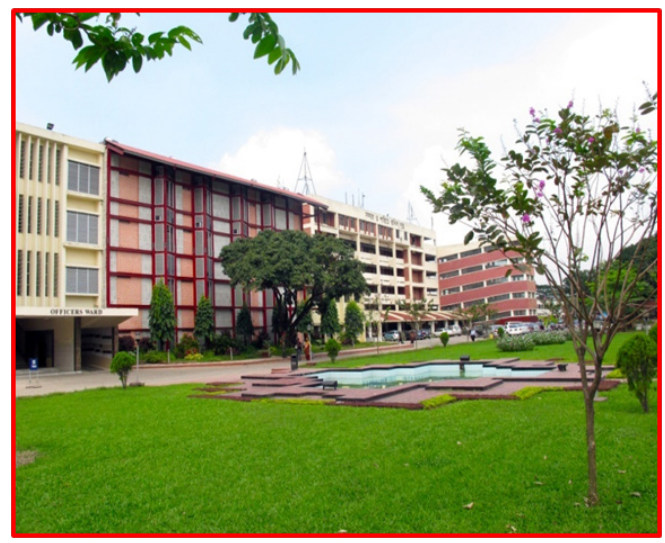

Figure I Combined Military Hospital (CMH), Dhaka.

\section{The incidence of surgical diseases}

On an average 100 routine pediatric surgery cases are being performed in every month. Amongst those commonly performing and less commonly performing operations are as follows in Table 1, (Figures 2-5).

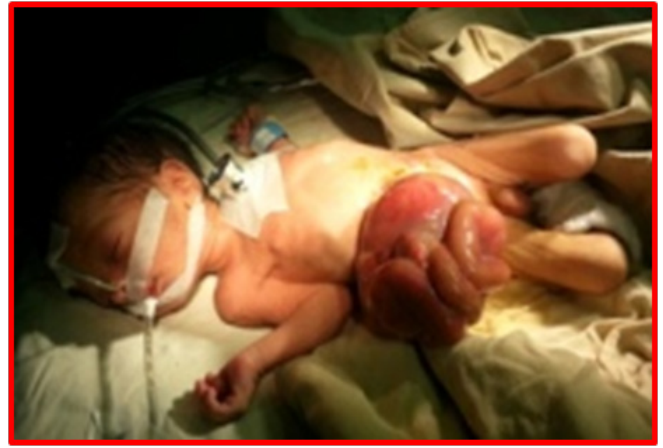

Figure 2 Incidence of surgical diseases.

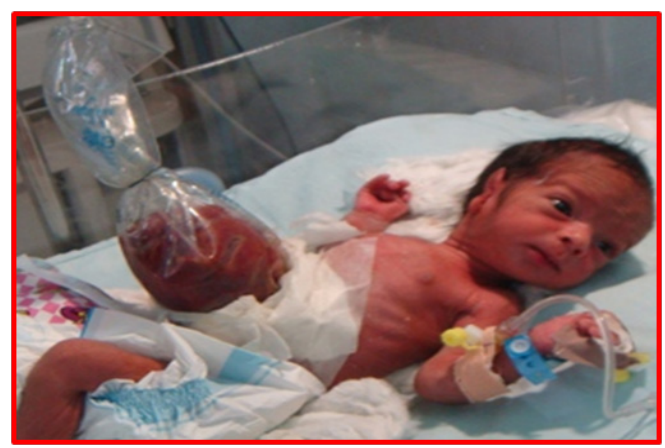

Figure 3 Incidence of surgical diseases.

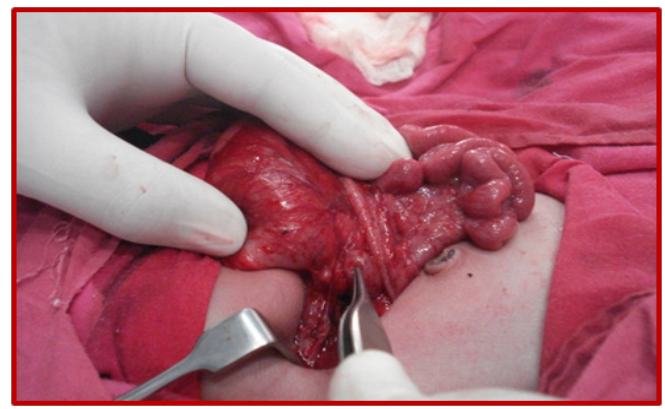

Figure 4 Incidence of surgical diseases.
$\mathrm{CMH}$, Dhaka has 36 beds adult ICU, 15 beds medical and 15 beds surgical HDU's and 10 beds neonatal \& 10 beds pediatrics ICU as well (Table 2).

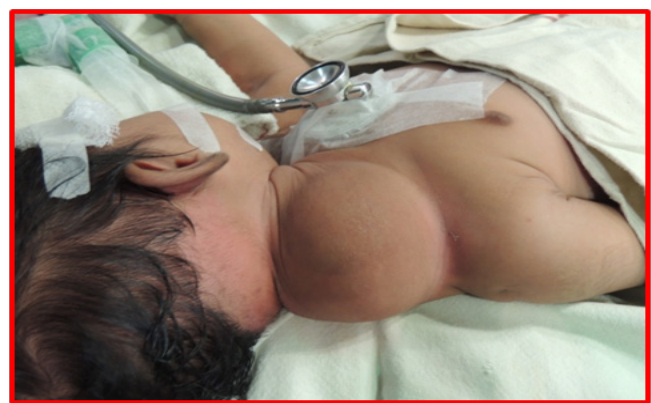

Figure 5 Incidence of surgical diseases.

Table I Common surgical diseases \& operations are

\begin{tabular}{ll}
\hline Diseases & Operations \\
\hline Hernia & Herniotomy \\
ARM & PSARP \& ASARP \\
Hirschsprung's disease & Colostomy \& pull-through operations \\
Intussusceptions & Laparotomy and resection \& anastomosis \\
Rectal polyp & Excision \\
IHPS & Pyloromyotomy \\
Hydrocephalus & V-P shunt \\
Hypospadias & Urethroplasty \\
Tongue tie & The release of tongue tie \\
Appendicitis & Appendectomy \\
\hline
\end{tabular}

Table 2 Less common surgical diseases \& operations are

\begin{tabular}{ll}
\hline Diseases & Operations \\
\hline Esophageal atresia with/without fistula & End to end anastomosis \\
Intestinal atresia & Resection and anastomosis \\
A diaphragmatic hernia & Repair of a hernia \\
Eventration of diaphragm & Repair \\
Mesenteric cyst & Excision \\
Myelomeningocele & Repair \\
Gastroschisis & Laparotomy \\
Omphalocele & Laparotomy \\
PUV & Fulguration \\
UDT & Orchidopexy \\
\hline
\end{tabular}

\section{Dhaka shishu children hospital}

Dhaka Shishu Hospital is a 560 beds tertiary care teaching hospital having 06 operation theatres and 12 beds paediatric ICU (Figure 6). ${ }^{2}$

\section{Concerns \& challenges}

Though these hospitals have enough hospital beds and plenty of patients yet lack skill doctors \& paramedics. In terms of patients, these hospitals are managing a maximum number of patients with

${ }^{2}$ Logbook. Dhaka Shishu (Children) Hospital, Dhaka; 2016. 
minimum resources and staffs. To develop skilled manpower there is no alternative to train doctors as well as paramedics and attending seminars \& conferences to update knowledge \& skill.

a. Decentralization of administration, capacity building and organized health management system is still going on

b. Poor socioeconomic state

c. Poor nutrition and multiple pregnancies

d. Insufficient antenatal screening in rural areas

e. Social awareness, various superstitions, social customs \& traditions in rural areas are a barrier for maternal \& child health

f. Delayed reporting sick to the hospital and delayed interventions

g. Urban women are working and adopting family planning, so demand for treatment is increasing

h. Universal precaution and awareness for infection control is insufficient in theater \& ICU

i. Don't have the provision of autoclaving used anesthesia instruments for every patient in theaters

j. Though most of our hospitals are a general hospital with inadequate specialized facilities, we are trying to provide specialized treatment

k. Majority of the pediatrics surgical cases are coming from poor socio-economic classes, so getting less priority

\section{Day to day improvisations}

a. Maintaining airway by placing a soft saline bag under the neck

b. Warming babies by room heater/warm clothes instead of the radiant warmer/warming blanket

c. Warming fluid and blood by dipping loop of an infusion set inside a hot saline bag

d. Clinical monitoring of oxygenation, ventilation, circulation, and temperature

e. Repeated use of one time used anesthesia kits

f. Improvisation of regional anesthesia kits

g. Equipment's for proper positioning of patients not available (Figure 7) (Figure 8) (Table 3).

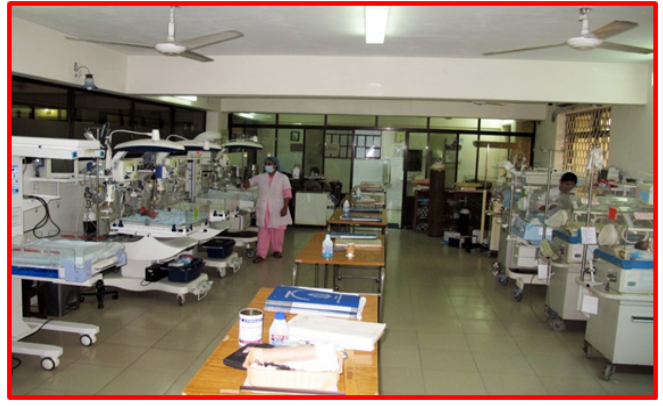

Figure 6 Operation theatre \& ICU setup of CMH, Dhaka.

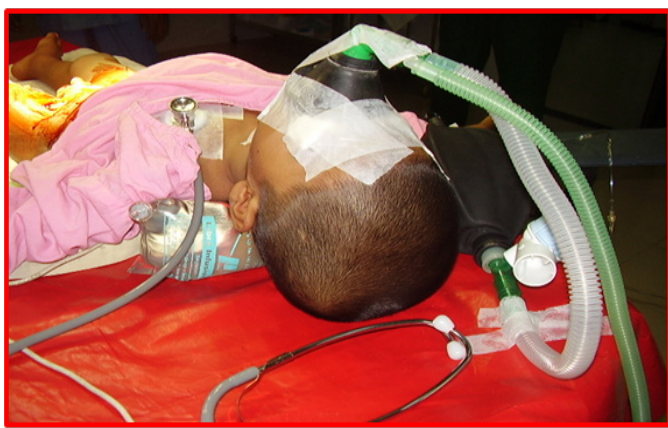

Figure 7 Maintaining airway by placing a soft saline bag under the neck.

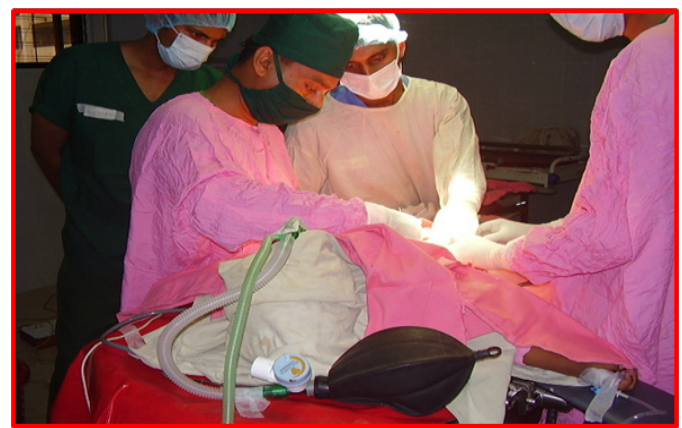

Figure 8 Equipment's for proper positioning of patients.

Table 3 Statistics of neonatal surgery in 2016 at Dhaka Shishu (Children) Hospital

\begin{tabular}{lll} 
Month & Number of operations & Number of death \\
\hline January & 78 & 12 \\
February & 64 & 9 \\
March & 62 & 13 \\
April & 60 & 10 \\
May & 67 & 14 \\
June & 70 & 13 \\
July & 74 & 11 \\
August & 69 & 9 \\
September & 72 & 10 \\
October & 66 & 8 \\
November & 57 & 6 \\
December & 63 & 15 \\
\hline
\end{tabular}

\section{Outcome}

\section{Causes of death in Dhaka children hospital}

a. Delayed reporting sick and delayed intervention

b. Complex medical diseases \& co-morbidity

c. Ongoing sepsis \& multi-resistant organisms

d. Hospital set-up is not well equipped

e. Peripheral hospitals are neither well prepared \& equipped nor having trained staffs

f. Maternal causes: poor nutrition, preterm, multiple pregnancies

\section{Causes of less death in military hospitals}

Military hospitals having a very effective chain of evacuation system from field hospital to base hospital is the reason for fewer casualties in military hospitals (Table 4).

Table 4 Statistics of neonatal surgery from 2012 to 2016 at CMH, Dhak

\begin{tabular}{lll} 
SI. & Number of operation & Number of death \\
\hline 2012 & 28 & 3 \\
2013 & 31 & 5 \\
& 35 & 8 \\
2015 & 43 & 7 \\
2016 & 37 & 6 \\
\hline
\end{tabular}




\section{Conclusion}

The hospital is rich with allied health professionals in almost all discipline especially pediatrics cardiology, pediatrics cardiac surgery. Though these hospitals have enough hospital beds and plenty of patients yet lack skill doctors \& paramedics. In terms of patients, these hospitals are managing a maximum number of patients with minimum resources and staffs. Professional challenges are like capacity building, poor socioeconomic and poor nutritional status, inadequate social awareness programs, delayed reporting sick to hospital \& delayed interventions, extreme resources constraints and to combat those challenges day to day improvisations are like improvised way of maintaining airway, improvisation of warming up patients, fluids, blood and clinical monitoring of patients instead of sophisticated electronic monitoring devices.

\section{Acknowledgements}

None.

\section{Conflict of interest}

Author declares that there is no conflict of interest. 